\title{
Effects of Perfluorooctane sulfonate on immobilization, heartbeat, reproductive and biochemical performance of Daphnia magna
}

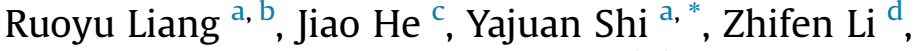 \\ Suriyanarayanan Sarvajayakesavalu ${ }^{\text {a, e }}$, Yvette Baninla ${ }^{\mathrm{a}, \mathrm{b}}$, Feifan Guo ${ }^{\mathrm{f}}$, Juan Chen ${ }^{\mathrm{a}, \mathrm{b}}$, \\ Xiangbo $\mathrm{Xu}^{\mathrm{g}}$, Yonglong $\mathrm{Lu}^{\mathrm{a}}$, b \\ a State Key Laboratory of Urban and Regional Ecology, Research Centre for Eco-Environmental Sciences, Chinese Academy of Sciences, Beijing, 100085, China \\ ${ }^{\mathrm{b}}$ University of Chinese Academy of Sciences, Beijing, 100049, China \\ c College of Resources and Environmental Sciences, China Agriculture University, Beijing, 100193, China \\ ' Shandong Xiehe University, Shandong, 250107, China \\ e SCOPE (Scientific Committee on Problems of the Environment) Beijing Office, Beijing, 100085, China \\ ${ }^{\mathrm{f}}$ Beijing Sustainable Green Energy ET. Co., Ltd, 100192, China \\ g School of Environment \& Natural Resources, Renmin University of China, Beijing, 100059, China
}

\section{H I G H L I G H T S}

- Heartbeat of Daphnia magna exposed to PFOS $48 \mathrm{~h}$ was stimulated significantly.

- $48 \mathrm{~h}-\mathrm{EC}_{50}$ was $79.35 \mathrm{mg} \mathrm{L} \mathrm{L}^{-1}$, the toxicity of PFOS was classified as intermediate.

- Intrinsic rate of natural increase was a sensitive parameter.

- Reproductive, antioxidant and neurological responses were significantly inhibited.

- At $8 \mathrm{mg} \mathrm{L}^{-1}$ concentration, most evaluated endpoints have sensitive effects.

\section{A R T I C L E I N F O}

Article history:

Received 30 September 2016

Received in revised form

27 November 2016

Accepted 28 November 2016

Available online 7 December 2016

Handling Editor: Shane Snyder

\section{Keywords:}

PFOS

Daphnia magna

Reproduction

Heartbeat

Enzyme activity

\section{G R A P H I C A L A B S T R A C T}

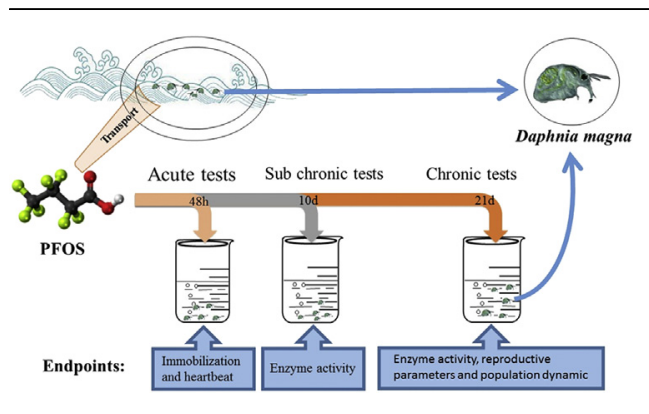

\begin{abstract}
A B S T R A C T
In recent years, Perfluorooctane sulfonate (PFOS) was widely detected in Yellow-Bohai Sea and other areas, causing a series of adverse effects in aquatic organisms. However, present studies of its chronic and acute toxicity on aquatic organisms were far more inadequate. Therefore, in the present study, Daphnia magna was used to investigate PFOS toxicity on their immobilization, heartbeat, reproductive and biochemical performance in acute, subchronic and chronic exposure. The results showed that the $48 \mathrm{~h}-$ $\mathrm{EC}_{50}$ value for immobilization was $79.35 \mathrm{mg} \mathrm{L}^{-1}$ and the toxicity was classified as intermediate. Heartbeat was significantly stimulated and reproductive parameters were significantly suppressed by PFOS, which can be used to reflect the toxicological effects on individuals. On the other hand, intrinsic rate of natural increase was more sensitive than reproductive parameters, which indicated negative responses on population dynamics of Daphnia magna. In addition, there were different degrees of inhibition on GST, CAT and ChE activity, which indicated three types of enzyme could become biomarkers to chronic PFOS
\end{abstract}

\footnotetext{
* Corresponding author.

E-mail address: yajuanshi@rcees.ac.cn (Y. Shi).
} 
exposure. Most of selected and evaluated endpoints have significant sensitivity to PFOS at the concentration of $8 \mathrm{mg} \mathrm{L}^{-1}$ during subchronic and chronic exposure.

() 2016 Elsevier Ltd. All rights reserved.

\section{Introduction}

Perfluorooctane sulfonate (PFOS) is one of the most difficult to degrade synthetic chemicals that has become a ubiquitous environmental contaminant. PFOS is used as a chemical material in diverse industrial products and daily necessity, including textiles, papermaking, electronics and pharmaceutical industry (Lau et al., 2007; Supreeyasunthorn et al., 2016). Based on the properties of stability, persistence, biological accumulation and toxicity, PFOS was listed in Stockholm Convention on Persistent Organic Pollutants (Wang et al., 2009; Chen et al., 2014; Jantzen et al., 2016; Salgado et al., 2016). Although PFOS was hydrophobic, it has the water-soluble functional groups, which differs from other typical persistent organic pollutants.

This feature of PFOS leads that PFOS has high solubility in water and it can exist in aquatic ecosystem for a long time. Previous published scientific studies reported that PFOS exists widely in rivers, lakes and oceans (Yamashita et al., 2005; Munoz et al., 2015; Sakurai et al., 2016). Considering Yellow-Bohai Sea as a case area, the maximal concentration in sea water of PFOS was reported to be about $30.9 \mathrm{ng} \mathrm{L}^{-1}$ in coastal areas of Bohai Sea (Wang et al., 2011). The findings of previous research also reported that PFOS was detected from 0.35 to $47 \mathrm{ng} \mathrm{L}^{-1}$ along the West Coast of Korea (Naile et al., 2010, 2013). In recent decades, elevated levels of PFOS has been detected in many freshwater animals, which has accumulated and biomagnified in the marine food chain (Bossi et al., 2005; Yeung et al., 2009; Renzi et al., 2013). Therefore, toxic effects of PFOS on aquatic organisms were significant for providing scientific basis for risk assessment.

Daphnia magna is an aquatic animal with reproductive capabilities and feeds on algae, which has been widely applied to chemicals toxicity tests. Due to its sensibility to pollutants in the environment, Daphnia magna was selected as an international standard experimental organisms (Seda and Petrusek, 2011). A number of current studies on Daphnia magna are concentrated on indicators such as immobilization, reproductive parameters and bioaccumulation of pollutants (OECD, 2004; Giesy et al., 2010; Home and Directorate, 2013). However, few studies have explored the heartbeat and intrinsic rate of nature increase of Daphnia magna and used heart rate and intrinsic rate as evaluating indicators. A $10 \mathrm{~d}$ subchronic test added to chronic exposure may reflect the toxicological process better, which is in contrast with the $21 \mathrm{~d}$ test duration in traditional method.

Since PFOS is frequently accumulated in aquatic ecosystem, it is necessary to understand the real aquatic ecological risks and toxicological effects of PFOS. This research attempts to use acute and chronic toxicity test methods to investigate PFOS toxicity on Daphnia magna after different exposure periods, including a $48 \mathrm{~h}$ acute toxicity test, $10 \mathrm{~d}$ subchronic and $21 \mathrm{~d}$ chronic toxicity tests. Afterwards, immobilization and heart rate were measured after acute exposure. Intrinsic rate of nature increase was calculated to reflect that population of Daphnia magna made responses to PFOS. Moreover, reproductive parameters and enzyme activities of glutathione-S-transferase (GST), catalase (CAT) and cholinesterase (ChE) were determined in order to explore chronic toxicological effects of PFOS. The result of the present study is expected to provide additional useful information for environmental monitoring and the effective prevention of water pollution.

\section{Materials and method}

\subsection{Experimental chemicals and reagents}

Perfluorooctane sulfonic acid potassium salt (CAS: No. 2795-393 , $\geq 98 \%$ purity) was purchased from Fluka (Sigma-Aldrich, Switzerland. Tris), CDNB and Insect AChE ELISA Kit (REF: E-59928) were obtained from Sigma Chemical (St. Louis, MO, U.S.A.). GSH (CAS: No.70-18-8) was purchased from JKHD. Tissue protein extraction kit was obtained from CWBIO. BG11 and M4 culture medium were prepared by analysis of reagents of Sinopharm group. All working stock solutions were made instantly before the tests.

\subsection{Experimental organisms and culture conditions}

Daphnia magna was obtained from State Key Laboratory of Environmental Aquatic Chemistry (Eco-Environmental Sciences of Chinese Academy of Sciences, Beijing). Daphnia magna was maintained in artificial medium M4 at $20^{\circ} \mathrm{C}$ with pH 7 in the laboratory (Revel et al., 2015). Green algae (Scenedesmus obliquus) that was used as food for Daphnia magna was purchased from Institute of Hydrobiology (Chinese Academy of Sciences, Wuhan) and cultivated in artificial medium BG11 (Singh et al., 2014). The Daphnia magna used in this experiment was grown at a density of 1 animal per $40 \mathrm{~mL}$ in $1 \mathrm{~L}$ bottles at $20 \pm 1{ }^{\circ} \mathrm{C}$ under a $16: 8 \mathrm{~h}$ light and each one was given algal cultures at a concentration of 90,000 cells $\mathrm{mL}^{-1}$. The culture medium was renewed twice a week.

\subsection{Experimental design}

\subsubsection{Acute toxicity tests}

The acute toxicity tests were conducted on the grounds of OECD guidelines that were aimed to check acute toxicity of water quality to Daphnia magna (OECD, 2004). Preliminary experiment was carried to determine official experimental range of concentration level. Five neonates were put in $80 \mathrm{~mL}$ containers with M4 medium for $48 \mathrm{~h}$. PFOS (concentrations of $0,50,100,150,200$ and $250 \mathrm{mg} \mathrm{L}^{-1}$ ) was also added into each container. Three repetitions were carried for preliminary experiment and also to the control groups. The result of preliminary experiment showed highest concentration to be $150 \mathrm{mg} \mathrm{L}^{-1}$. Therefore, five neonates were placed in $80 \mathrm{~mL}$ bottles exposed to different concentrations of PFOS $\left(0,30,44,66,100,150 \mathrm{mg} \mathrm{L}^{-1}\right)$ for $48 \mathrm{~h}$. Five repetitions per treatments and control groups were carried. Daphnia magna were not provided with algal cultures during acute exposure. The number of immobile Daphnia magna was counted in order to calculate $\mathrm{EC}_{50}$ of immobilization after $48 \mathrm{~h}$.

\subsubsection{Subchronic and chronic toxicity tests}

According to the results of acute toxicity tests, six concentration gradients of PFOS $\left(0,1,2,4,8,16 \mathrm{mg} \mathrm{L}^{-1}\right)$ were designed for chronic tests. The experimental design requires that the highest concentration of chronic experiment is lower than $\mathrm{EC}_{50}$ in acute experiment. Ten replicates with one neonate per $80 \mathrm{~mL}$ beaker and control groups were exposed to mentioned concentrations of PFOS 
for $21 \mathrm{~d}$. During this period, Daphnia magna were fed with algal cultures twice daily and the culture water was also renewed twice daily. The beakers were changed with new ones because of sorption of PFOS onto the glass on the tenth day. The mortality, activity, condition and reproduction of Daphnia magna were observed and recorded every day, and newborn were also counted and removed daily. All of test subjects were maintained under the same room temperature. After the long exposure time of 10 and $21 \mathrm{~d}$, only survival Daphnia magna was analyzed from biological and chemical aspects and the enzymes activity of GST, CAT and ChE were tested respectively. The chronic exposure tests were repeated at least 3 times during the test period.

\subsection{Immobilization and heart rate recording}

$\mathrm{EC}_{50}$ is the value of concentration of PFOS, when activity of the half Daphnia magna was inhibited (50\%). With a glass rod gently touching the beaker, the movement distance of Daphnia magna is less than the length of themselves in $15 \mathrm{~s}$. Daphnia magna was confirmed to be immobile. The number and percentage of immobile fleas were recorded to calculate $\mathrm{EC}_{50}$ after $48 \mathrm{~h}$ acute toxic experiment. The value of $\mathrm{EC}_{50}$ was determined following a modified Karber method (Hamilton et al., 1978). The formula was used to calculate $\mathrm{EC}_{50}$ as follows:

$\operatorname{lnEC}_{50}=X_{k}-d\left(\sum_{i}^{n} \mathrm{P}_{i}-0.5\right)$

where $X_{k}$ is the concentration of PFOS corresponding to the immobilization rate of $100 \%$ and $d$ is the sum of each immobilization rate of each treatment group.

After $48 \mathrm{~h}$ acute tests, the heart rate of Daphnia magna exposed to every treatment was recorded as a video ( $50 \mathrm{fps}$ ) by digital videotape that was mounted on the inverted microscope. The video played in slow motion, and the heart jump of live fleas was counted within $60 \mathrm{~s}$ to figure out the heart rate by watching videos.

\subsection{Mortality, reproductive parameters and population growth}

The long-term impacts on mortality, growth and reproduction of Daphnia magna exposed to PFOS were observed by checking parent animals and living neonates daily. In the course of the experiment, the days to first brood and quantity of first brood were recorded and counted. After $21 \mathrm{~d}$ tests, the number of dead parent fleas was counted for mortality rate.

Intrinsic rate of natural increase was regarded as an important indicator to reflect dynamic population changes. The following formula was used to calculate the intrinsic rate of natural increase of Daphnia magna (Jeong et al., 2016):

$\sum l_{x} m_{x} e^{-r x}=1$

where $l_{x}$ is the proportion of individuals surviving to age $x, m_{x}$ is the mean number of living later generations produced each parent at age $\mathrm{x}$, and $\mathrm{x}$ represents the number of days in the experiment.

\subsection{Enzymes activities assay}

Protein concentrations and GST, CAT and ChE enzyme activities were measured on tenth day and twenty-first day in chronic toxicity tests. Tissue protein extraction kit effectively extracts protein from Daphnia magna. Protein concentrations were measured by the bicinchoninic acid (BCA) protein assay (Reichelt et al., 2016).

GST activity was measured using a modified version of assay proposed by Baldwin et al. (Baldwin and Ga., 1996). GST can efficiently catalyze and reduce the combination of GSH and 1chloride-2,4-dinitrobenzene (CDNB). The absorbance value of reaction product reached the maximum, when the wave length was $340 \mathrm{~nm}$. Therefore, we put $5 \mathrm{mM}$ Tris ( $\mathrm{pH} 7.0$ ), $5 \mu \mathrm{M}$ CDNB and $5 \mu \mathrm{g}$ protein samples in 96 well plates. Subsequently, an enzyme-labeled instrument was used to monitor the increasing in absorbance at $340 \mathrm{~nm}$ over $25^{\circ} \mathrm{C}$ to get the activity of GST.

Enzymes CAT can efficiently decompose hydrogen peroxide into hydrogen and water. The absorbance value of reaction products reached the maximum, when the wave length was $240 \mathrm{~nm}$. Therefore, we mixed $120 \mu \mathrm{L}$ Tris ( $\mathrm{pH}$ 7.4) and $5 \mu \mathrm{g}$ protein samples in 96 well plates. The mixture was heated for 25 min on water bath at $37^{\circ} \mathrm{C}$ and then $30 \mu \mathrm{L}$ hydrogen peroxide was added to plates. The samples were put in enzyme-labeled instrument under $240 \mathrm{~nm}$ in order to get changes of absorbance in the per unit time.

ChE activity was measured according to the ChE enzyme-linked immunosorbent assay (ELISA). Purified ChE antibody, test samples and standard products were added to the wells. Horseradish peroxidase (HRP) was also added into the wells to obtain an indicator that can gauge concentrations of $\mathrm{ChE}$ in samples.

\subsection{Data analysis}

In acute and chronic toxicity experiments for Daphnia magna exposed to PFOS, the data were subjected to Student's t-test and analysis of variance (ANOVA) to determine significant difference between experimental groups and control groups at 0.01 and 0.05 significance level. All statistical analyses were performed with Statistical Product and Service Solutions Ver. 13.0 (SPSS 13.0) for Windows.

\section{Results and discussion}

\subsection{Immobilization and heartbeat}

Immobilization of Daphnia magna affected by different PFOS concentrations were presented in Fig. 1. Increasing concentration of PFOS resulted in the increasing inhibition of Daphnia magna. No obvious adverse reactions of Daphnia magna were found, when the concentration was lower than $30 \mathrm{mg} \mathrm{L}^{-1}$. Almost all Daphnia magna stayed immobile, when the concentration was higher than $150 \mathrm{mg} \mathrm{L}^{-1}$.

Effective concentration is usually used to reflect toxicity of pollutants to test organisms. $\mathrm{EC}_{50}$ was chosen to observe and

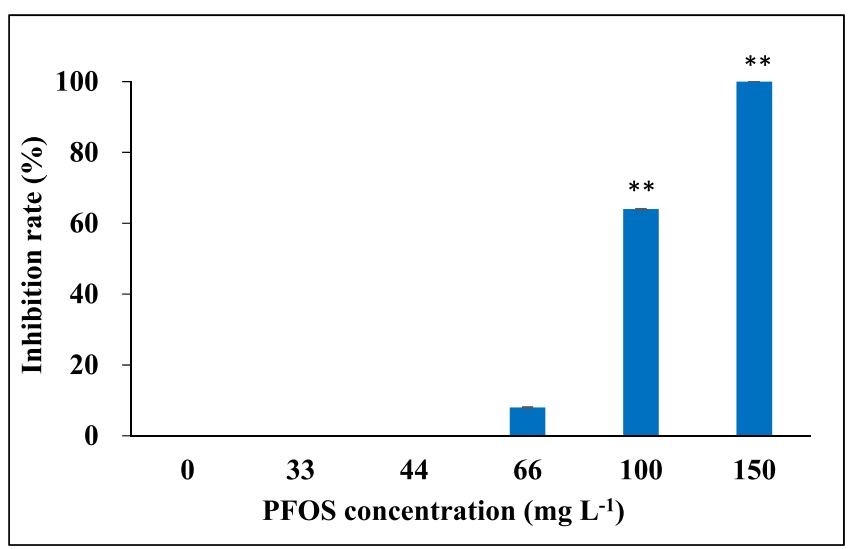

Fig. 1. Inhibition rate of Daphnia magna exposed to PFOS after $48 \mathrm{~h}$. Sample size of each treatment is 25 . Values represent mean \pm standard deviation; Asterisk $\left({ }^{*}\right)$ denotes a significant difference from check group $(\mathrm{p}<0.05)$ and asterisks $\left({ }^{* *}\right)$ denotes an extremely significant difference from check group $(\mathrm{p}<0.01)$. 


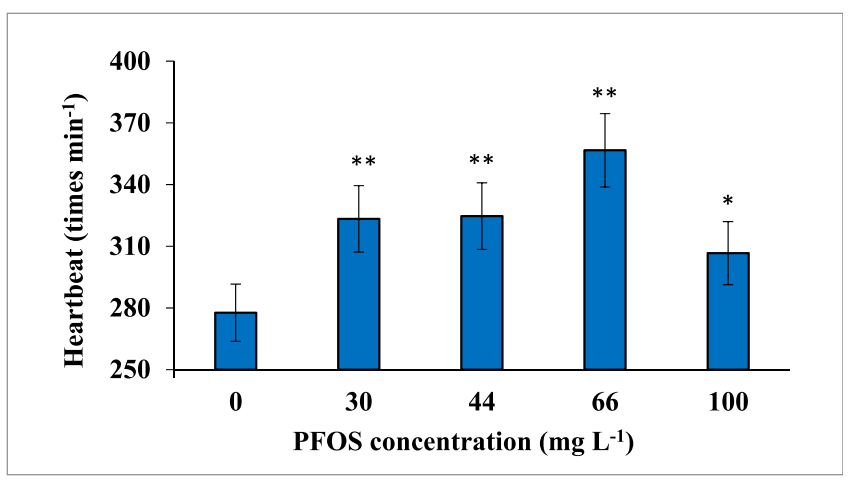

Fig. 2. Heart rate of Daphnia magna exposed to different concentrations of PFOS for $48 \mathrm{~h}$. Sample size of each treatment is 25 . Values represent mean \pm standard deviation; Asterisk $\left({ }^{*}\right)$ denotes a significant difference from check group $(\mathrm{p}<0.05)$ and asterisks $\left(^{* *}\right)$ denotes an extremely significant difference from check group $(\mathrm{p}<0.01)$.

determine the effects of pollutants on the immobilization of Daphnia magna following OECD guideline for the testing of Chemicals (OECD, 2004).

According to statistics of $48 \mathrm{~h}$ acute tests, acute toxicity effects of PFOS on the immobilization were observed and compared. The result showed that the $48 \mathrm{~h}-\mathrm{EC}_{50}$ was calculated to be equal to $79.35 \mathrm{mg} \mathrm{L}^{-1}$, which agreed with the finding of Lazhar $\mathrm{M}\left(\mathrm{EC}_{50}\right.$ : 80.22-95.36 $\mathrm{mg} \mathrm{L}^{-1}$ ) (Mhadhbi et al., 2010). Based on the guidelines for the hazard evaluation of new chemical substances, the toxicity of PFOS should be classified as intermediate. In general, the presence of PFOS in the environmental dose may not cause acute toxicity in a short period of exposure.

As shown in Fig. 2, the significance of heartbeat was also increased in contrast with control groups along the increase of the concentrations of PFOS. Furthermore, it is obvious that the heart rate reached the maximum under $66 \mathrm{mg} \mathrm{L}^{-1}$ PFOS. When the concentration reached $100 \mathrm{mg} \mathrm{L}^{-1}$, the frequency of heartbeat decreased. However, the frequency at $100 \mathrm{mg} \mathrm{L}^{-1}$ was still significantly greater than control groups. Heart rate is usually used in pharmacology and toxicology studies. Increasing concentration of PFOS stimulated heartbeat, but at the high concentration state inhibits the heart rate. One of few published articles relating to heartbeat reported that Ectoine has toxic influence on Daphnia magna and heart rate kept being inhibited in 48 h tests (Bownik et al., 2015). Until now, researches about the impacts of PFOS on heartbeat are not enough. The previous research provided evidence that heart rate may be related to the distance between different heart chambers, which contracted cardiac muscle (Huang et al., 2011). Therefore, heart rate may be a sensitive physiological indicator that can reflect the degree of the pollutants to the blood circulation system of Daphnia magna. As a result, we recommend heartbeat as an indicator in toxicity evaluation of Daphnia magna.

\subsection{Mortality, reproductive performance and population growth}

After $21 \mathrm{~d}$ exposure of different concentrations of PFOS, the results were presented in Table 1 . The mortality and reproductive performance has been influenced under different concentrations of PFOS. No death of Daphnia magna was observed, when the concentration of PFOS was less than $1 \mathrm{mg} \mathrm{L}^{-1}$. With increased PFOS, almost all Daphnia magna died due to poisonous effects.

As shown in Table 1, the difference of days to first brood with control groups has no significance $(p>0.05)$ when PFOS concentrations were from 1 to $4 \mathrm{mg} \mathrm{L}^{-1}$. The endpoints of most reproductive parameters were significantly suppressed by PFOS at $8 \mathrm{mg} \mathrm{L}^{-1}$. Higher concentrations of PFOS delayed time of first litter. This tendency was consistent with earlier observations, in which toxicity usually prolonged the time of flea reproduction (Ji et al., 2008). The quantity of first brood decreased initially and then rose and fell as the concentration increased. At concentration of $2 \mathrm{mg} \mathrm{L}^{-1}$, Daphnia magna continuously exposed to PFOS seems to adapt, which may cause a fractional rise.

The intrinsic rate of natural increase is a kind of ecological index, which reflects the comprehensive ability to survive and reproduce. With the increase of exposure concentration, intrinsic rate of natural increase dropped sharply at concentrations from 1 to $16 \mathrm{mg} \mathrm{L}^{-1}$ and reached the significant level at 8 and $16 \mathrm{mg} \mathrm{L}^{-1}$ when compared to control groups. Higher concentrations of PFOS could make intrinsic rate of natural increase lower, threatening the survival and reproduction of the Daphnia magna population. As time went on, self-defense mechanism failed to resist toxicity of PFOS. Intrinsic rate of Daphnia magna reduced significantly with increasing dose of other toxicants like Propanil, which agrees with the results of Villarroel et al. (2004). The results mentioned above suggest that the growth and reproductive performance of Daphnia magna are sensitive to PFOS and can be used to evaluate its toxicity in aquatic ecosystem.

\subsection{Antioxidant and neurological responses}

GST and CAT were assessed to reflect the response of antioxidant enzymes to PFOS(Gómez-Oliván et al., 2014; Yu et al., 2014). While exposed to toxicants, the body produces oxidative stress and the balance of active oxygen is broken. ChE plays a crucial role in the stability of nervous system and was chosen to be measured and analyzed during $10 \mathrm{~d}$ and $21 \mathrm{~d}$ exposure periods (Liu et al., 2012).

GST is one of the most important metabolic enzymes, which is also involved in the detoxification (Liu et al., 2006). The enzymatic activity determination was presented in Fig. 3. The GST activity of Daphnia magna was increased after a $10 \mathrm{~d}$ exposure, by $3.6 \%$ compared to the control groups at the concentration of $4 \mathrm{mg} \mathrm{L}^{-1}$. When the PFOS concentration was beyond $4 \mathrm{mg} \mathrm{L}^{-1}$, GST activity was inhibited. While the PFOS concentration was 8 and $16 \mathrm{mg} \mathrm{L}^{-1}$, the GST activity reached the significant level. After a $21 \mathrm{~d}$ exposure of Daphnia Magna to PFOS, the GST activities of different groups

Table 1

Mortality, reproductive and population parameters of Daphnia magna after $21 \mathrm{~d}$ exposure to PFOS.

\begin{tabular}{|c|c|c|c|c|}
\hline PFOS $\left(\mathrm{mg} \mathrm{L}^{-1}\right)$ & Mortality of parent flea (\%) & Days to first brood (d) & Quantity of first brood & Intrinsic rate $(r)$ \\
\hline 0 & 0 & $10.30 \pm 0.48$ & $20.60 \pm 5.93$ & 0.2397 \\
\hline 1 & 0 & $10.80 \pm 0.42$ & $18.40 \pm 6.11$ & 0.2399 \\
\hline 2 & 10 & $10.89 \pm 0.33$ & $20.78 \pm 5.54$ & 0.2363 \\
\hline 4 & 10 & $10.89 \pm 0.33$ & $17.67 \pm 5.43$ & 0.2252 \\
\hline 8 & 30 & $11.00 \pm 0.00^{* *}$ & $17.00 \pm 3.74$ & $0.2270^{* *}$ \\
\hline 16 & 90 & $11.00 \pm 0.00$ & $11.00 \pm 0.00^{* *}$ & $0.1965^{* *}$ \\
\hline
\end{tabular}

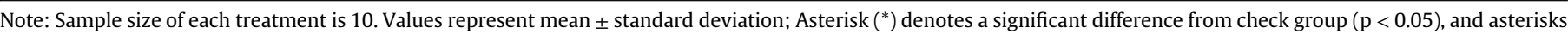
$\left.{ }^{* *}\right)$ denotes an extremely significant difference from check group $(\mathrm{p}<0.01)$. 


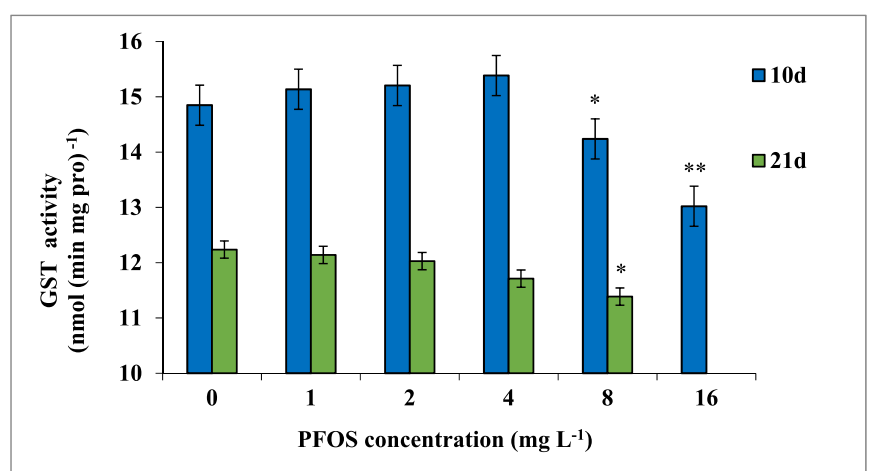

Fig. 3. GST activity of Daphnia magna exposed to various concentrations of PFOS after subchronic and chronic tests. Asterisk $\left({ }^{*}\right)$ denotes a significant difference from check group ( $\mathrm{p}<0.05)$, and asterisks $\left(^{* *}\right)$ denotes an extremely significant difference from check group $(\mathrm{p}<0.01)$.

were lower than corresponding $10 \mathrm{~d}$ results. As the exposed concentration increased, the GST activity fell continuously. At the concentration of $8 \mathrm{mg} \mathrm{L}^{-1}$, the GST activity gets to the significant level. The reason is the dead of Daphnia Magna, which resulted that enzyme activity could not be determined at the concentration of $16 \mathrm{mg} \mathrm{L}^{-1}$. In $21 \mathrm{~d}$ chronic tests, the GST activity had the inhibition process, which is similar to $10 \mathrm{~d}$ chronic tests. This inhibition process of the GST activity may be explained that toxicants inhibit the production or transportation of oxidative metabolites. The decrease of GST activity was consistent with similar observations in previous findings. For example, a recent research reported that the GST activity of mice exposed to PFOS decreased significantly and agreed well with our result (Zhang et al., 2013). A reduction in GST may indicate Daphnia magna failed to detoxicate and resist oxidative stress in the cell (Santos et al., 2004). However, the variation of GST activity can be influenced by many factors, including $\mathrm{pH}$, temperature, and toxicity (Wang et al., 2011). The result of GST assay indicated that GST may be used as a biomarker for the evaluation of organic pollutants in aquatic ecosystem.

CAT is a key enzyme in the antioxidant system and it can be increased under various environmental stress (Alberto et al., 2011). CAT decomposes hydrogen peroxide in metabolic waste and protects organs and cells from injury caused by hydrogen peroxide. After $10 \mathrm{~d}$ exposure, the significant changes were not found in enzyme activity of CAT with the concentrations from 1 to $8 \mathrm{mg} \mathrm{L}^{-1}$ (Fig. 4). When the concentration of PFOS reached $16 \mathrm{mg} \mathrm{L}^{-1}$, the CAT activity was significantly lower than control groups, and the reduction was $31.5 \%$. Daphnia magna has not adapted to the

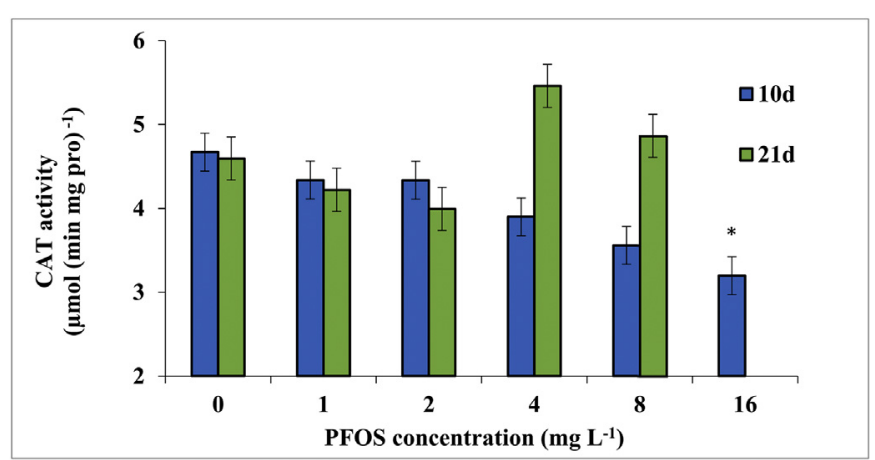

Fig. 4. CAT activity of Daphnia magna exposed to various concentrations of PFOS after subchronic and chronic tests. Asterisk $\left({ }^{*}\right)$ denotes a significant difference from check group ( $\mathrm{p}<0.05$ ), and asterisks $\left({ }^{* *}\right)$ denotes an extremely significant difference from check group $(\mathrm{p}<0.01)$.

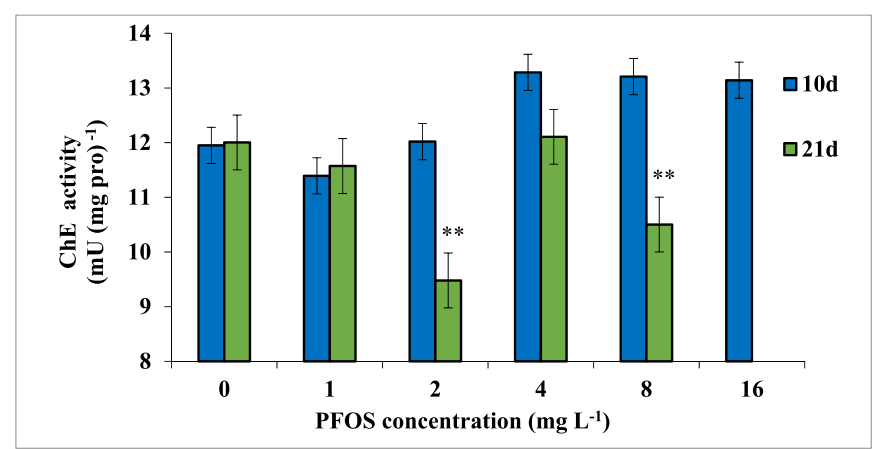

Fig. 5. ChE enzyme activity of Daphnia magna exposed to various concentrations of PFOS after chronic tests. Asterisk $\left({ }^{*}\right)$ denotes a significant difference from check group $(\mathrm{p}<0.05)$, and asterisks $\left(^{* *}\right)$ denotes an extremely significant difference from check group $(\mathrm{p}<0.01)$

external environmental pressure, thereby reducing CAT activity. After $21 \mathrm{~d}$ exposure, the CAT activity showed a trend of fluctuation. It is noteworthy that CAT activity at 4 and $8 \mathrm{mg} \mathrm{L}^{-1}$ of $21 \mathrm{~d}$ tests was higher than other treatments, which possibly reflected that PFOS provoked CAT to enhance the ability of scavenging free radicals. More $\mathrm{H}_{2} \mathrm{O}_{2}$ and $\mathrm{O}_{2}$ were formed which enhanced this ability and cause a decrease in CAT activity. CAT plays an important part in antioxidant system, which guards the first defense line against oxygen toxicity (Li et al., 2011). When PFOS concentration exceeded the tolerance range, the defense process would be destroyed. However, the mechanism of antioxidant defense system in Daphnia magna exposed to PFOS needs to be further explored. Compared to $21 \mathrm{~d}$ tests, the $10 \mathrm{~d}$ enzyme analysis was propitious to explore dose effect of CAT activity.

The ChE activities assay was presented in Fig. 5. In $10 \mathrm{~d}$ exposure to various concentrations of PFOS, the ChE activities of Daphnia magna was decreased initially and then increased. There was no significant difference between every treatment and control groups. PFOS, accumulated in a subchronic period, has a slight effect on the conduction of nerve signals. In $21 \mathrm{~d}$ exposure to different concentrations of PFOS, the tendency of ChE of Daphnia magna activities were similar to $10 \mathrm{~d}$ results. In contrast with $10 \mathrm{~d}$ results, the change of ChE activity was easy to be observed in the $21 \mathrm{~d}$ tests. When the concentration was 2 and $8 \mathrm{mg} \mathrm{L}^{-1}$, the significant decrease was achieved. To ensure neural signal transmission, ChE was hydrolyzed by increasing enzyme activity at the increase of PFOS. When PFOS concentration was higher than $16 \mathrm{mg} \mathrm{L}^{-1}$, almost all Daphnia magna were died. This shows that the PFOS concentration exceeded the tolerance range of Daphnia magna. The results showed that the activity of ChE in Daphnia magna under the action of selfadjustment remains stable in the short term. At the low pollution concentration, neurotransmitter can be normal transmission by self-adjustment. However, nerve transfer process will be affected at the high concentration. Although the functions of neurobehaviours exposed to PFOS are lacking, it is proposed that interactions with neurotransmitter may be used to explain toxicological effects of PFOS on ChE (Gee and Moser, 2008). Therefore, with the support of present findings, the $21 \mathrm{~d}$ ChE activity may be applied to the environmental impact assessment of PFOS pollution.

\section{Conclusions}

Toxicological effects of PFOS on Daphnia magna under acute, subchronic and chronic exposure were explored and discussed in this study. In $48 \mathrm{~h}$ acute experiment of Daphnia magna to various concentrations of PFOS, $\mathrm{EC}_{50}$ for immobilization was calculated as 
$79.35 \mathrm{mg} \mathrm{L}^{-1}$ and the toxicity was classified as intermediate. PFOS can strongly stimulate the Daphnia Magna's heartbeat, making heart rate sensitive to be used as the endpoint of evaluation. In chronic exposure of Daphnia magna to PFOS, reproductive parameters, including days to first brood, quantity of first brood and intrinsic rate were well reflecting the toxicity of PFOS. The intrinsic rate were confirmed to be more sensitive than days and quantity of first brood. The activity of GST was significantly inhibited by high concentration of PFOS in $10 \mathrm{~d}$ and $21 \mathrm{~d}$ exposure. CAT was significantly inhibited in short exposure and antioxidant system of Daphnia magna was destroyed in long time exposure to PFOS. Significant inhibition of $\mathrm{ChE}$ occurred under the long term exposure of PFOS. At the level of $8 \mathrm{mg} \mathrm{L}^{-1}$ PFOS concentration during subchronic and chronic exposure, most of selected evaluated endpoints of Daphnia magna have sensitive effects, which should be a call for concern. The results of the present findings may be applied to ecological evaluation of environmental risk of PFOS. It is expected that there may be potential ecological toxicity of PFOS under sufficient exposure time, and the further research on ecological risk caused by PFOS should be undertaken.

\section{Acknowledgements}

The authors are grateful for the support provided by the National Natural Science Foundation of China (Grant No. 41271487; No. 41671483), Ministry of sciences and Technology (2013FY111100-02), and Ministry of Agriculture (Grant No. 201303106).

\section{References}

Alberto, A.C., Rocío, O.B., Fernando, M.J., 2011. Age effect on the antioxidant activity of Daphnia magna (Anomopoda: daphniidae): does younger mean more sensitivity? J. Environ. Biol. 32, 481-487.

Baldwin, W.S., Ga., L.B., 1996. Expression and induction of an immunochemically related class of glutathione S-transferases in Daphnia magna. Comp. Biochem. Physiol. Part B Biochem. Mol. Biol. 113, 261-267.

Bossi, R., Riget, F.F., Dietz, R., Sonne, C., Fauser, P., Dam, M., Vorkamp, K., 2005. Preliminary screening of perfluorooctane sulfonate (PFOS) and other fluorochemicals in fish, birds and marine mammals from Greenland and the Faroe Islands. Environ. Pollut. 136, 323-329.

Bownik, A., Stepniewska, Z., Skowronski, T., 2015. Effects of ectoine on behavioural, physiological and biochemical parameters of Daphnia magna. Comp. Biochem. Physiol. Toxicol. Pharmacol. CBP 168, 2-10.

Chen, J., Tanguay, R.L., Tal, T.L., Gai, Z., Ma, X., Bai, C., Tilton, S.C., Jin, D., Yang, D., Huang, C., Dong, Q., 2014. Early life perfluorooctanesulphonic acid (PFOS) exposure impairs zebrafish organogenesis. Aquat. Toxicol. 150, 124-132.

Gómez-Oliván, L.M., Galar-Martínez, M., García-Medina, S., Valdés-Alanís, A., IslasFlores, H., Neri-Cruz, N., 2014. Genotoxic response and oxidative stress induced by diclofenac, ibuprofen and naproxen in Daphnia magna. Drug Chem. Toxicol. 37, 391-399.

Gee, J.R., Moser, V.C., 2008. Acute postnatal exposure to brominated diphenylether 47 delays neuromotor ontogeny and alters motor activity in mice. Neurotoxicol. Teratol. 30, 79-87.

Giesy, J.P., Naile, J.E., Khim, J.S., Jones, P.D., Newsted, J.L., 2010. Aquatic toxicology of perfluorinated chemicals. Rev. Environ. Contam. Toxicol. 202, 1-52.

Hamilton, M.A., Russo, R.C., Thurston, R.V., 1978. Trimmed spearman-karber method for estimating median lethal concentrations in toxicity bioassays. Environ. Sci. Technol. 12, 714-719.

Home, O., Directorate, E., 2013. OECD guidelines for the testing of chemicals. Methods Mol. Biol. 947, 37-56.

Huang, Q., Chao, F., Wu, X., Fan, J., Dong, S., 2011. Perfluorooctane sulfonate impairs the cardiac development of a marine medaka (Oryzias melastigma). Aquat. Toxicol. 105, 71-77.

Jantzen, C.E., Annunziato, K.A., Bugel, S.M., Cooper, K.R., 2016. PFOS, PFNA, and PFOA sub-lethal exposure to embryonic zebrafish have different toxicity profiles in terms of morphometrics, behavior and gene expression. Aquat. Toxicol. 175, $160-170$.

Jeong, T.Y., Yuk, M.S., Jeon, J., Kim, S.D., 2016. Multigenerational effect of perfluorooctane sulfonate (PFOS) on the individual fitness and population growth of Daphnia magna. Sci. Total Environ. 569-570, 1553-1560.

Ji, K., Kim, Y., Oh, S., Ahn, B., Jo, H., Choi, K., 2008. Toxicity of perfluorooctane sulfonic acid and perfluorooctanoic acid on freshwater macroinvertebrates (Daphnia magna and Moina macrocopa) and fish (Oryzias latipes) $\dagger$. Environ.
Toxicol. Chem. 27, 2159-2168.

Lau, C., Anitole, K., Hodes, C., Lai, D., Pfahles-Hutchens, A., Seed, J., 2007. Perfluoroalkyl acids: a review of monitoring and toxicological findings. Toxicol. sci. Off. J. Soc. Toxicol. 99, 366-394.

Li, Z.H., Zlabek, V., Velisek, J., Grabic, R., Machova, J., Kolarova, J., Li, P., Randak, T., 2011. Acute toxicity of carbamazepine to juvenile rainbow trout (Oncorhynchus mykiss): effects on antioxidant responses, hematological parameters and hepatic EROD. Ecotoxicol. Environ. Saf. 74, 319-327.

Liu, H., Wang, W., Zhang, J.F., Wang, X.R., 2006. Effects of copper and its ethylenediaminetetraacetate complex on the antioxidant defenses of the goldfish, Carassius auratus. Ecotoxicol. Environ. Saf. 65, 350-354.

Liu, H., Yuan, B., Li, S., 2012. Altered quantities and in vivo activities of cholinesterase from Daphnia magna in sub-lethal exposure to organophosphorus insecticides. Ecotoxicol. Environ. Saf. 80, 118-125.

Mhadhbi, L., Fernandez, S.P., Conde, D.R., Boumaiza, M., Beiras, R., 2010. Acute toxicity of perfluorooctane sulfonic acid on early life stages of Daphnia magna, siriella armata, Paracentrotus Lividus sea urchin, and turbot (Scophthalmus Maximus L.). Nat. Preced. 99, 385-389.

Munoz, G., Giraudel, J.L., Botta, F., Lestremau, F., Devier, M.H., Budzinski, H. Labadie, P., 2015. Spatial distribution and partitioning behavior of selected polyand perfluoroalkyl substances in freshwater ecosystems: a French nationwide survey. Sci. total Environ. 517, 48-56.

Naile, J.E., Khim, J.S., Hong, S., Park, J., Kwon, B.O., Ryu, J.S., Hwang, J.H., Jones, P.D. Giesy, J.P., 2013. Distributions and bioconcentration characteristics of perfluorinated compounds in environmental samples collected from the west coast of Korea. Chemosphere 90, 387-394.

Naile, J.E., Khim, J.S., Wang, T., Chen, C., Luo, W., Kwon, B.O., Park, J., Koh, C.H. Jones, P.D., Lu, Y., Giesy, J.P., 2010. Perfluorinated compounds in water, sediment, soil and biota from estuarine and coastal areas of Korea. Environ. Pollut. 158, 1237-1244.

OECD, 2004. Test No. 202: Daphnia sp. Acute Immobilisation Test. OECD Publishing, pp. $1-12$

Reichelt, W.N., Waldschitz, D., Herwig, C., Neutsch, L., 2016. Bioprocess monitoring: minimizing sample matrix effects for total protein quantification with bicinchoninic acid assay. J. Ind. Microbiol. Biotechnol. 43, 1271-1280.

Renzi, M., Guerranti, C., Giovani, A., Perra, G., Focardi, S.E., 2013. Perfluorinated compounds: levels, trophic web enrichments and human dietary intakes in transitional water ecosystems. Mar. Pollut. Bull. 76, 146-157.

Revel, M., Fournier, M., Robidoux, P.Y., 2015. Single-walled carbon nanotubes toxicity to the freshwater amphipod Hyalella azteca: influence of sediment and exposure duration. J. Xenobiotics 5.

Sakurai, T., Serizawa, S., Kobayashi, J., Kodama, K., Lee, J.H., Maki, H., Zushi, Y. Sevilla-Nastor, J.B., Imaizumi, Y., Suzuki, N., Horiguchi, T., Shiraishi, H., 2016 Temporal trends for inflow of perfluorooctanesulfonate (PFOS) and perfluorooctanoate (PFOA) to Tokyo Bay, Japan, estimated by a receptor-oriented approach. Sci. total Environ. 539, 277-285.

Salgado, R., López-Doval, S., Pereiro, N., Lafuente, A., 2016. Perfluorooctane sulfonate (PFOS) exposure could modify the dopaminergic system in several limbic brain regions. Toxicol. Lett. 240, 226-235.

Santos, M.A., Pacheco, M., Ahmad, I., 2004. Anguilla anguilla L. antioxidants responses to in situ bleached kraft pulp mill effluent outlet exposure. Environ. Int. 30, 301-308.

Seda, J., Petrusek, A., 2011. Daphnia as a model organism in limnology and aquatic biology: some aspects of its reproduction and development. J. Limnol. 70, 335

Singh, P. Guldhe, A., Kumari, S., Rawat, I., Bux, F., 2014. Investigation of combined effect of nitrogen, phosphorus and iron on lipid productivity of microalgae Ankistrodesmus falcatus KJ671624 using response surface methodology. Biochem. Eng. J. 94, 22-29.

Supreeyasunthorn, P., Boontanon, S.K., Boontanon, N., 2016. Perfluorooctane sulfonate (PFOS) and perfluorooctanoic acid (PFOA) contamination from textiles. J. Environ. Sci. Health Part A 51, 472-477.

Villarroel, M.J., Sancho, E., Ferrando, M.D., Andreu, E., 2004. Acute, chronic and sublethal effects of the herbicide propanil on Daphnia magna. Chemosphere 53, 857-864.

Wang, T., Wang, Y., Liao, C., Cai, Y., Jiang, G., 2009. Perspectives on the inclusion of perfluorooctane sulfonate into the Stockholm convention on persistent organic pollutants. Environ. Sci. Technol. 43, 5171-5175.

Wang, Y.Y., Sun, H.S., Zhou, Y.J., Yan, D.C., Wang, L., 2011. The effect of environmental factors on the activities of glutathione S-transferases in haemolymph of scallop Chlamys farreri. Mar. Sci. 35, 52-56.

Yamashita, N., Kannan, K., Taniyasu, S., Horii, Y., Petrick, G., Gamo, T., 2005. A global survey of perfluorinated acids in oceans. Mar. Pollut. Bull. 51, 658-668.

Yeung, L.W., Yamashita, N., Taniyasu, S., Lam, P.K., Sinha, R.K., Borole, D.V. Kannan, K., 2009. A survey of perfluorinated compounds in surface water and biota including dolphins from the Ganges River and in other waterbodies in India. Chemosphere 76, 55-62.

Yu, T.H., Dafre, A.L., Umbuzeiro, G.D.A., Franciscon, E., 2014. CYP-dependent induction of glutathione S-transferase in Daphnia similis exposed to a disperse azo dye. Ecotoxicology 24, 232-237.

Zhang, Y.H., Wang, J., Dong, G.H., Liu, M.M., Wang, D., Zheng, L., Jin, Y.H., 2013. Mechanism of perfluorooctanesulfonate (PFOS)-induced apoptosis in the immunocyte. J. Immunotoxicol. 10, 49-58. 